\title{
Research into reducing inland water damage inside large-scale storage pipe basins
}

\author{
M. Onishi \\ Japan Institute of Wastewater Engineering and Technology, Japan
}

\begin{abstract}
The large-scale water storage pipes taken as the subject of this study have basins of at least 4,000 ha and are connected to numerous main sewers/pump stations. Therefore, operation of the storage pipes to make maximum use of the storage effect is a complex challenge. This research aimed to conduct a study for efficient operation of each pump station and effective use of main lines in regard to various rainfalls in a large-scale storage pipe basin. We confirmed that it would be possible to shut down pump stations during construction, if the pump station needs to be reconstructed, by connecting multiple pump stations with a network of the large-storage pipe across a drainage area. The simulation results also verified that this design method is effective for the maximum recorded rainfall, which exceeds the target design rainfall. This is considered to be because actual rain does not uniformly fall over a basin (rainfall tends to be unevenly distributed), and so a network effect between pump stations is displayed in which low-operating pump stations are compensated for by other pump stations. The methods for effective use resulting from this research are considered to be widely applicable, and we intend to confirm these results in other basins in the future.
\end{abstract}

Keywords: network of large-scale water storage pipes, large-scale stormwater.

\section{Introduction}

The large-scale water storage pipes that form the subject of this study have basins of at least 4,000 ha and are connected to numerous main sewers/pump stations, making operation of the storage pipes that maximizes the storage effect a complex challenge. We attempted to study efficient operation of each pump 
station and the effective use of main lines with regards to various rainfalls in a large-scale storage pipe basin.

\section{Study of network pipes between pump stations}

An overview of the large-scale storage pipe studied is shown in Table 1, and an overview of the water catchment area is shown Figure 1.

A runoff factor of 0.85 was used to design the storage pipe for the relevant basin, but the actual runoff factor was maintained at approximately 0.6 by restricting the development of the area to conserve nature or secure green space if the decision were to be made to carry out development. The large-scale storage pipe was designed with a runoff design factor of 0.85 and is thus expected to have extra capacity of approximately $1.0 \times 105 \mathrm{~m}^{3}$ when the runoff factor is changed to 0.6 .

During our research, we studied whether it would be possible to prevent flooding during a rainfall event by using this extra storage capacity and constructing a network between pump stations, even in the event that the pump station was shut down for an extended period.

Table 1: Overview of large-scale storage pipe.

\begin{tabular}{|l|l|}
\hline Pipe diameter & $\varphi 3000-8500$ \\
\hline Extension & Approx. $14.8 \mathrm{~km}$ \\
\hline Storage capacity & Approx. $4.1 \times 10^{5} \mathrm{~m}^{3}$ \\
\hline
\end{tabular}

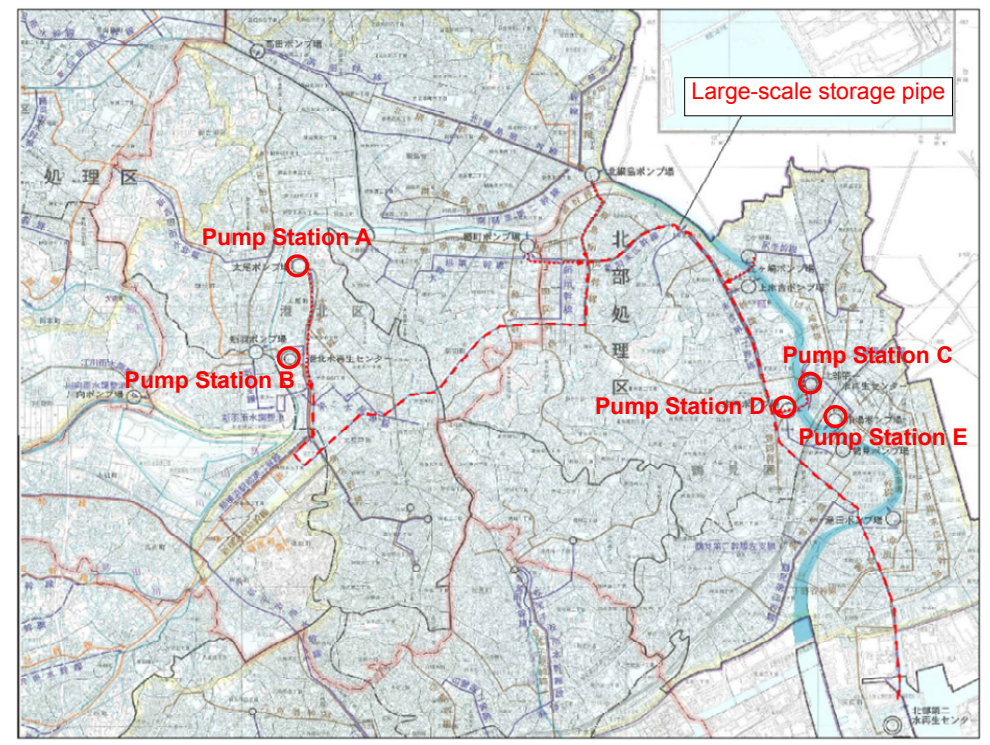

Figure 1: Overview of water catchment area and pump station locations for the large-scale storage pipe. 


\subsection{Study into the shutdown of Pump Station A}

An overview of the sewer plan for the area surrounding Pump Station A and Pump Station B is shown in Figure 2 below.

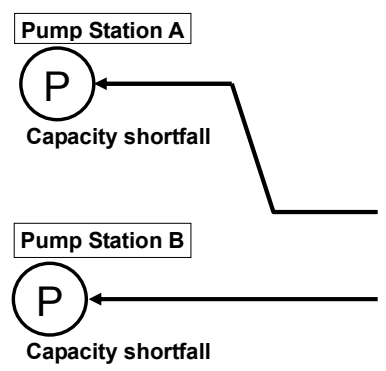

Before installation of the large-scale storage pipe

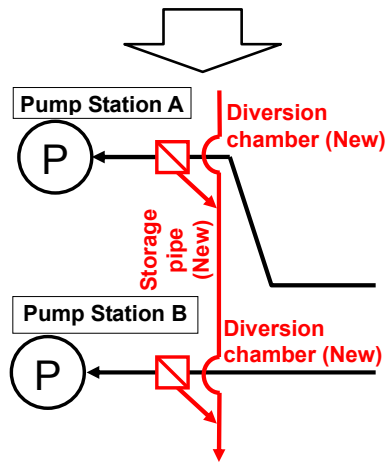

After installation of the large-scale storage pipe (current state)

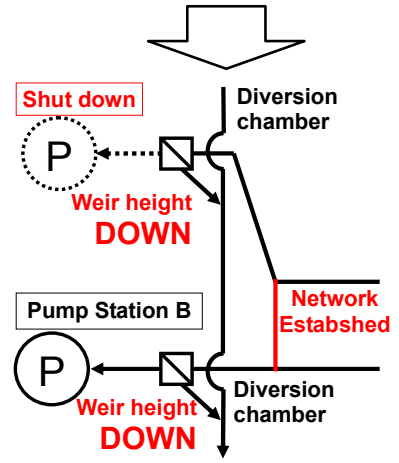

Plan for the shutdown of Pump Station A

Figure 2: Overview of sewer plan for the area surrounding Pump Station A and Pump Station B. 
Here, Infoworks was used as a rainfall runoff analysis simulation model.

The design rainfall for a 10-year storm event was also used as the target rainfall. The design rainfall for a 10 -year storm event was obtained using the following equation:

$$
I=\frac{1452}{t^{0.70}+7.5}(57.9 \mathrm{~mm} / \mathrm{hr})
$$

(I: Average rainfall intensity (mm/hr), t: Rainfall duration (min))

The result of simulation in which the target rainfall was applied to the current sewer pipes is shown in Figure 3. A capacity shortfall in both Pump Station A and Pump Station B resulted in the flooding of upstream areas.

With the aim of preventing flooding, simulation was carried out for a situation in which a large-scale storage pipe was installed. The result of this simulation is shown in Figure 4, and it was found that flooding can be prevented by installing the pipe.

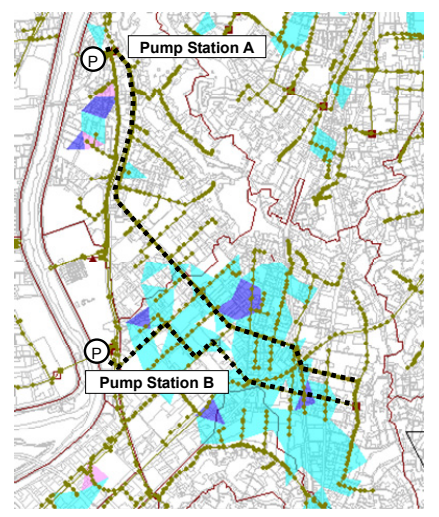

Figure 3: Before installation of the large-scale storage pipe.

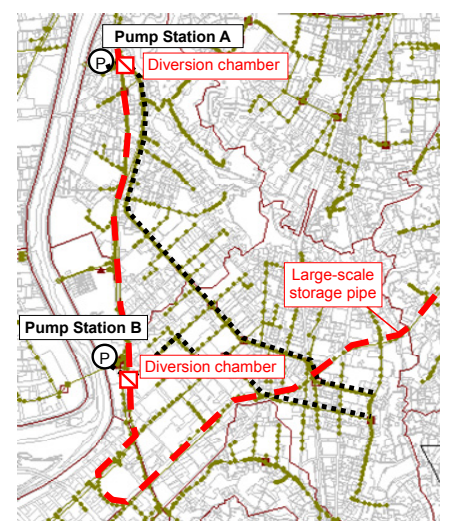

Figure 4: After installation of the large-scale storage pipe (current state). 
Pump Station A is also scheduled to be reconstructed and shut down for a long period of time, but even in this situation flooding needs to be controlled for the target rainfall.

A simulation was carried out under conditions where Pump Station A was shut down. In this plan, a network pipe was installed upstream in order to use Pump Station B at its maximum capacity.

The result of the simulation showed that there was an increase in the inflow from the diversion chamber of Pump Station A system to the storage pipe as well as the inflow to Pump Station B through network pipes (see Table 2).

The discharge volume of Pump Station A is $1.2 \times 105 \mathrm{~m}^{3}$, which exceeds the extra storage volume of $1.0 \times 105 \mathrm{~m}^{3}$ in the large-scale storage pipe. However, the network pipe allows Pump Station B to take a portion of the discharge, resulting in an increase in the storage volume to about $1.0 \times 105 \mathrm{~m}^{3}$.

If Pump Station A is shut down, flooding occurs at some locations (see Figure 5). Therefore, the weir height of the diversion chamber is set to be lower in order to prevent this flooding (see Figure 6).

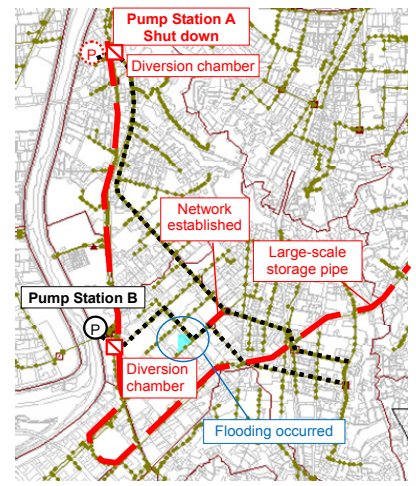

Figure 5: Plan for the shutdown of Pump Station A.

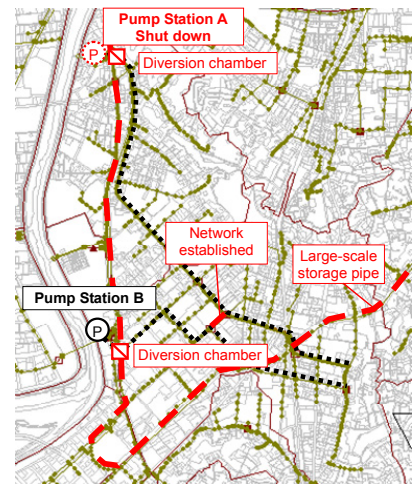

Figure 6: Plan for the shutdown of Pump Station A. (The weir height of the diversion chamber is changed.) 
Table 2: Water flow balance associated with the shutdown of Pump Station A.

\begin{tabular}{|l|c|c|c|c|c|c|}
\hline \multirow{2}{*}{$\begin{array}{l}\text { Pump } \\
\text { station }\end{array}$} & \multicolumn{2}{|c|}{$\begin{array}{c}\text { After installation of large-scale } \\
\text { storage pipe (current state) }\end{array}$} & \multicolumn{3}{|c|}{ Plan for the shutdown of Pump } \\
\cline { 2 - 7 } & $\begin{array}{c}\text { Pump } \\
\text { discharge } \\
\text { volume } \\
\left(\mathrm{m}^{3}\right)\end{array}$ & $\begin{array}{c}\text { Large- } \\
\text { scale } \\
\text { storage } \\
\text { pipe } \\
\text { inflow }\left(\mathrm{m}^{3}\right)\end{array}$ & Total & $\begin{array}{c}\text { Pump } \\
\text { discharge } \\
\text { volume } \\
\left(\mathrm{m}^{3}\right)\end{array}$ & $\begin{array}{c}\text { Large- } \\
\text { scale } \\
\text { storage } \\
\text { pipe } \\
\text { inflow }\left(\mathrm{m}^{3}\right)\end{array}$ & Total \\
\hline $\begin{array}{l}\text { Pump } \\
\text { Station A }\end{array}$ & 121,908 & 25,776 & 147,684 & 0 & 140,240 & 140,240 \\
\hline $\begin{array}{l}\text { Pump } \\
\text { Station B }\end{array}$ & 36,333 & 53,417 & 89,750 & 38,928 & 55,697 & 94,625 \\
\hline Total & 158,241 & 79,193 & 237,434 & 38,928 & 195,937 & 234,865 \\
\hline
\end{tabular}

Large-scale storage pipe inflow is increased by approx. $1.16 \times 105 \mathrm{~m}^{3}$. (Extra storage capacity of approx. $1.00 \times 105 \mathrm{~m}^{3}$.)

This result confirmed that Pump Station A can be reconstructed without causing flooding even if it is shut down under conditions such as a 10 -year storm event.

\subsection{Study into the shutdown of Pump Stations D and E}

An overview of the sewer plan for the area surrounding Pump Stations D and E is shown in Figure 7.

Currently, Pump Station C has extra capacity that was created by readjusting the runoff factor of the water catchment area.

The rainfall conditions for the target study are the same as in the study into the shutdown of Pump Station A in the previous section.

The simulation result for when the target rainfall is applied to the current sewer pipes is shown in Figure 8. The capacity shortfall in Pump Stations D and E resulted in the flooding of upstream areas.

With the aim of preventing flooding, simulation was carried out for the case in which the large-scale storage pipe was installed. The simulation result showed that flooding can be prevented by the installation of the pipe (see Figure 9).

In addition, during the reconstruction of Pump Stations D and E, network pipes that have extra capacity in order to prevent flooding during the target rainfall event are planned to be installed from Pump Stations D and E to Pump Station C. In these network pipes, the stormwater flows from Pump Stations D and E to Pump Station C when Pump Station C has extra capacity. However, the 

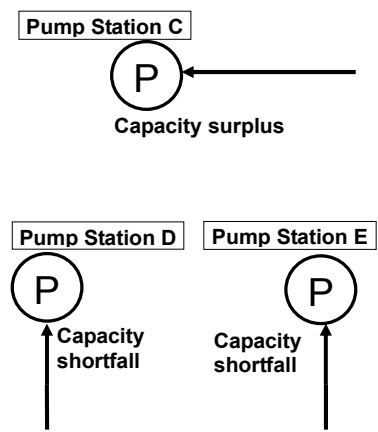

Before installation of the large-scale storage pipe
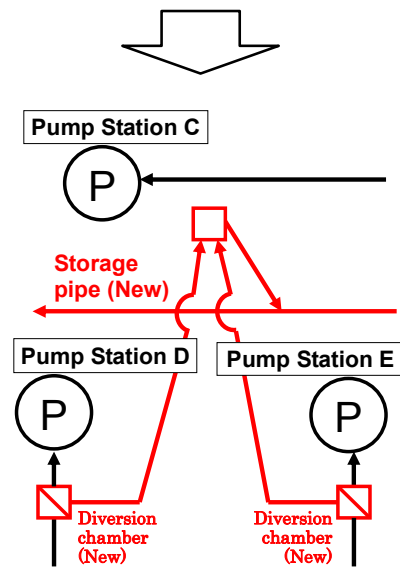

After installation of the large-scale storage pipe
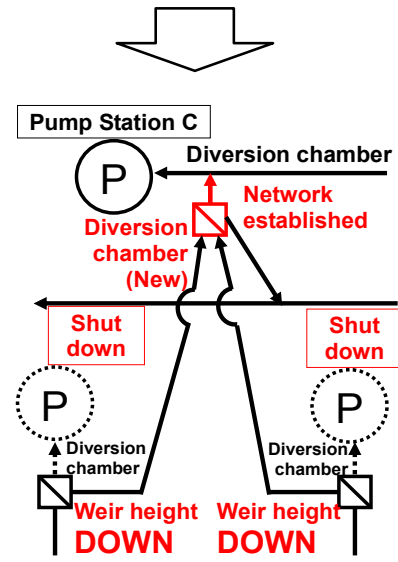

Plan for the shutdown of Pump Stations D and E

Figure 7: Overview of sewer plan for the area surrounding Pump Station C and Pump Stations D and E. 


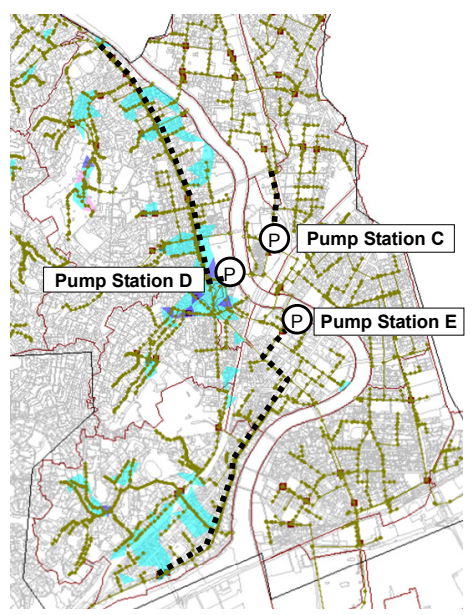

Figure 8: Before installation of the large-scale storage pipe.

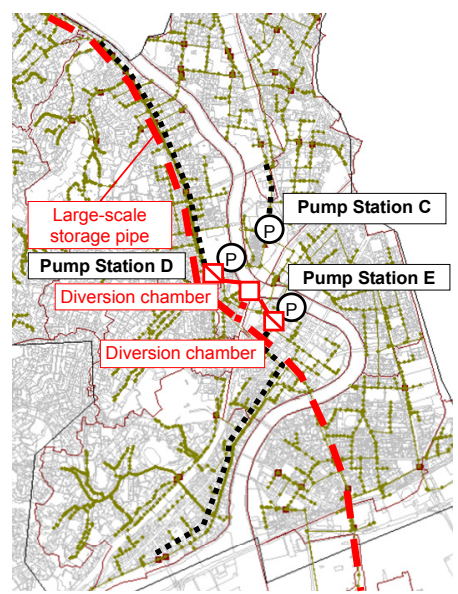

Figure 9: After installation of the large-scale storage pipe (current state).

stormwater flows in reverse and flows into the large-scale storage pipe as soon as the capacity of Pump Station $\mathrm{C}$ is fully used. The simulation result that was obtained under these conditions confirmed that it would be possible to shut down Pump Stations D and E without causing flooding (see Figure 10).

The results of simulation showed that there was an increase in the inflow from the diversion chamber of Pump Stations E and E to the storage pipe as well as the inflow to Pump Station C through the network pipe (see Table 3). 


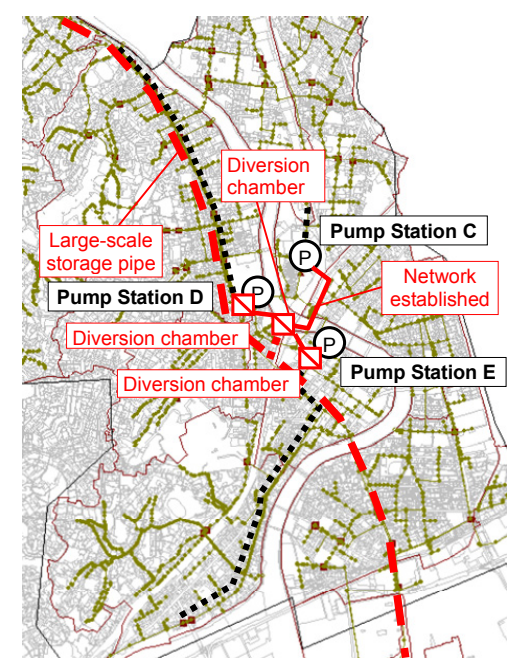

Figure 10: Plan for the shutdown of Pump Stations D and E.

Table 3: Water flow balance associated with the shutdown of Pump Stations $\mathrm{D}$ and $\mathrm{E}$.

\begin{tabular}{|c|c|c|c|c|c|c|}
\hline \multirow[b]{2}{*}{$\begin{array}{l}\text { Pump } \\
\text { station }\end{array}$} & \multicolumn{3}{|c|}{$\begin{array}{c}\text { Plan for the large-scale storage } \\
\text { pipe }\end{array}$} & \multicolumn{3}{|c|}{$\begin{array}{c}\text { Plan for the shutdown of Pump } \\
\text { Stations D and E }\end{array}$} \\
\hline & $\begin{array}{l}\text { Pump } \\
\text { discharge } \\
\text { volume } \\
\left(\mathrm{m}^{3}\right)\end{array}$ & $\begin{array}{l}\text { Large- } \\
\text { scale } \\
\text { storage } \\
\text { pipe } \\
\text { inflow } \\
\left(\mathrm{m}^{3}\right)\end{array}$ & Total & $\begin{array}{l}\text { Pump } \\
\text { discharge } \\
\text { volume } \\
\left(\mathrm{m}^{3}\right)\end{array}$ & $\begin{array}{l}\text { Large- } \\
\text { scale } \\
\text { storage } \\
\text { pipe } \\
\text { inflow } \\
\left(\mathrm{m}^{3}\right)\end{array}$ & Total \\
\hline $\begin{array}{c}\text { Pump } \\
\text { Station C }\end{array}$ & 187,171 & - & 187,171 & 245,566 & - & 245,566 \\
\hline $\begin{array}{c}\text { Pump } \\
\text { Station D }\end{array}$ & 60,399 & \multirow{2}{*}{13,391} & \multirow{2}{*}{98,692} & 0 & \multirow{2}{*}{30,667} & \multirow{2}{*}{30,667} \\
\hline $\begin{array}{c}\text { Pump } \\
\text { Station E }\end{array}$ & 24,902 & & & 0 & & \\
\hline Total & 272,472 & 13,391 & 285,863 & 245,566 & 30,667 & 276,233 \\
\hline
\end{tabular}

The large-scale storage pipe inflow is increased by approx. $1.70 \times 104 \mathrm{~m}^{3}$. (Extra storage capacity of approx. $1.00 \times 105 \mathrm{~m}^{3}$.) 
When the extra volume of the large-scale storage pipe is $1.0 \times 105 \mathrm{~m}^{3}$, the increase in storage volume due to the shutdown of a pump station remained at $1.7 \times 104 \mathrm{~m}^{3}$. This is because there was extra capacity in Pump Station C, into which the stormwater preferentially flowed. Also, if the rainfall intensity is higher in other areas, the stormwater preferentially flowed into the storage pipe that has extra capacity.

This result confirmed that Pump Stations D and E could be reconstructed without causing flooding even if they are shut down under conditions such as a 10 -year storm event.

\section{Response to excess rainfall}

A large-scale storage pipe was installed in order to prevent flooding if a 10-year storm event occurs. Currently, the storage capacity has a surplus of approximately $1.0 \times 105 \mathrm{~m} 3$, which was created by readjusting the runoff factor. We studied if this extra capacity would be enough to handle stormwater during a record-high rainfall (the maximum recorded rainfall).

The result of simulation for the maximum recorded rainfall showed that flooding would occur over a wide area (see Figure 11). However, serious flooding (flooding below floor level or higher) would occur only at three locations and there was no significant damage.

However, the result in Table 4 shows that the stormwater flowing into the storage would exceed the capacity of the storage pipe and the excess inflow would flow into the pump stations in other areas, which are connected by network pipes. The pump stations are connected the large-scale storage pipe network, and it is assumed that the stormwater flows from a pump station

Table 4: $\quad$ Storage capacity of large-scale storage pipe for the maximum recorded rainfall.

\begin{tabular}{|c|c|c|c|c|}
\hline $\begin{array}{l}\text { Target } \\
\text { rainfall }\end{array}$ & $\begin{array}{l}\text { Rainfall } \\
\text { intensity }\end{array}$ & $\begin{array}{l}\text { Additional } \\
\text { measures }\end{array}$ & $\begin{array}{l}\text { Large-scale } \\
\text { storage pipe } \\
\text { storage } \\
\text { volume }\end{array}$ & $\begin{array}{c}\text { Large-scale } \\
\text { storage pipe } \\
\text { extra } \\
\text { capacity }\end{array}$ \\
\hline $\begin{array}{c}\text { Design } \\
\text { rainfall for } \\
\text { a } 10 \text {-year } \\
\text { storm event }\end{array}$ & $58 \mathrm{~mm} / \mathrm{hr}$ & - & $\begin{array}{l}\text { Approx. } 3.08 \\
\quad \times 10^{5} \mathrm{~m}^{3}\end{array}$ & $\begin{array}{l}\text { Approx. } 1.00 \\
\quad \times 10^{5} \mathrm{~m}^{3}\end{array}$ \\
\hline \multirow[b]{2}{*}{$\begin{array}{l}\text { Excess } \\
\text { rainfall } \\
\text { (maximum } \\
\text { recorded } \\
\text { rainfall) }\end{array}$} & \multirow[b]{2}{*}{$75 \mathrm{~mm} / \mathrm{hr}$} & - & $\begin{array}{c}\text { Approx. } 5.92 \\
\text { x } 10^{5} \mathrm{~m}^{3}\end{array}$ & $\begin{array}{c}\text { Approx. } 1.84 \\
\times 10^{5} \mathrm{~m}^{3}\end{array}$ \\
\hline & & $\begin{array}{l}\text { Additional } \\
\text { measures for } \\
\text { preventing } \\
\text { flooding } \\
\text { below floor } \\
\text { level }\end{array}$ & $\begin{array}{l}\text { Approx. } 5.93 \\
\quad \times 10^{5} \mathrm{~m}^{3}\end{array}$ & $\begin{array}{l}\text { Approx. } 1.85 \\
\quad \times 10^{5} \mathrm{~m}^{3}\end{array}$ \\
\hline
\end{tabular}


without extra capacity to a pump station with extra capacity. Particularly, actual rainfall tends to be unevenly distributed over the area and creates extra capacity in either pump station, meaning that the installation of a network is considered to be very effective.

Figure 12 shows the results for when an additional measure (the addition of pipes) was taken in order to prevent serious flooding (i.e. three locations of flooding below floor level). The result also shows that the approximate cost of this measure is 300 million yen, and the implementation of a network is very effective with regards to management of excess rainfall that requires little effort.

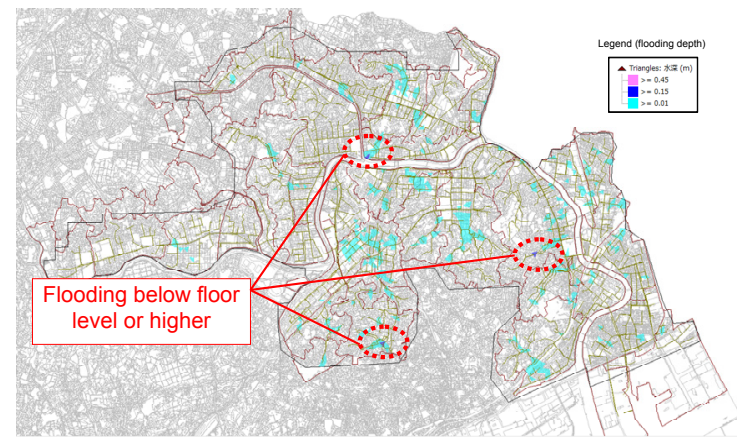

Figure 11: Result of runoff analysis simulation for the maximum recorded rainfall.

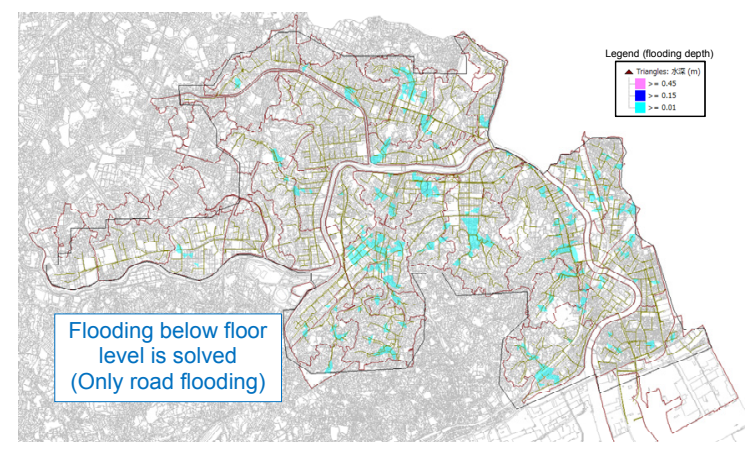

Figure 12: Result of runoff analysis simulation for the maximum recorded rainfall after taking additional measures.

\section{Summary}

We confirmed that it would be possible to shut down pump stations during construction, if the pump station needs to be reconstructed, by connecting multiple pump stations with a network of the large-storage pipe across a drainage area. 
The simulation results also verified that this design method is effective for the maximum recorded rainfall, which exceeds the target design rainfall. This is considered to be because actual rain does not uniformly fall over a basin (rainfall tends to be unevenly distributed), and so a network effect between pump stations is displayed in which low-operating pump stations are compensated for by other pump stations.

The methods for effective use resulting from this research are considered to be widely applicable, and we intend to confirm these results in other basins in the future.

\section{References}

[1] Japan Institute of Wastewater Engineering and Technology (JIWET), Leak Analysis Model Usage Manual, 2006

[2] Japan Institute of Wastewater Engineering and Technology (JIWET), Rainwater Pumping Station Network Design Manual, 2008

[3] Kobe City Construction Bureau, Construction of an Earthquake Resistant Sewerage Network System in Kobe, Journal for Civil Engineering, Office Space, pp. 44-47, 2011 